\title{
P300-tracking of changes in information processing / working memory in preclinical alzheimer's and mild cognitive impairments (MCI)
}

\author{
Miranda $\mathrm{P}^{1}$, Christopher D Cox ${ }^{1}$, Alexander $\mathrm{M}^{1}$, Jonathan RT Lakey ${ }^{1 *}$ and Danev $\mathrm{S}^{2}$ \\ ${ }^{1}$ Department of Surgery and Biomedical Engineering, University of California Irvine, California, USA \\ ${ }^{2}$ Medeia Inc, Santa Barbara, CA, USA
}

\begin{abstract}
Alzheimer's disease (AD) is a presently incurable disease with a significant health burden, with a prevalence of 5.8 million Americans as of 2019. Prognosis as well as more effective treatment regimens could be greatly augmented by reliable means of diagnosis in the earlier stages of development. Efforts to characterize impairments in memory in pre Clinical AD and mild cognitive impairment (MCI) range from the domain involved (episodic, semantic, working, perceptual, or visuospatial), to storage (sensory, long-term, short-term, explicit, implicit, autobiographical and morpheus), to memory processing including working memory or information processing (encoding, storage, and retrieval). An emerging area of research aims to determine whether detectable impairments in encoding, storage or retrieval have the ability to serve as hallmarks of pre Clinical Alzheimer's and early MCI giving both clinicians and patients a window of opportunity to halt or reverse progression to $\mathrm{AD}$ via early treatment options. For the identification of event related potential (ERP) markers, the P300 has shown promise as a state-of-the-art new device. While prolonged P300 latency recorded via electroencephalograph's (EEG) like BrainView NeuralScan is seen in normal aging, individuals with AD exhibit more prolonged P300 latencies and frontal-dominant P300 distribution when compared to normal individuals of the same age. Key questions now remaining include whether identification of these EEG hallmarks identified with the assistance of devices such as the P300 may provide us with an earlier timeframe in the diagnosis, prognosis and early treatment for $\mathrm{AD}$, as well as providing crucial insights into mechanisms of its early pathogenesis.
\end{abstract}

\section{Introduction}

Predicting the pre-clinical risk of Alzheimer's disease (AD) years in advance of the onset of symptoms would present patients and clinicians with a greatly extended window of opportunity to introduce lifestyle modifications or applicable treatments with a potential to ameliorate or delay the onset of the disease [1-3]. This comes in the wake of findings that primary prevention of $\mathrm{AD}$ is possible as among the risk factors for $\mathrm{AD}, 1 / 3^{\text {rd }}$ are modifiable and include metabolic syndrome and cardiovascular risk factors, lifestyle risk factors (physical inactivity, smoking), demographic factors like low education levels and depression [4-14]. "Pre-clinical AD" includes the presymptomatic individual who carries an autosomal dominant monogenic mutation and the "asymptomatic at risk state" includes the individual without the onset of clinical symptoms with the presence of any one of the current known biomarkers of $A D$ like amyloidosis in the brain with or without neurodegeneration $[2,4,15,16]$.

In terms of neurocognitive markers of $\mathrm{AD}$, episodic memory, psychomotor speed, and verbal fluency decline 5-8 years while others like concept formation show changes 10-17 years prior to the onset of dementia [17-19]. However, these neurocognitive markers are still considered relatively non-specific as they are also seen in depression, drug abuse, and Parkinson's disease [20-23]. Subjective cognitive decline (SCD), another candidate marker of pre-clinical $\mathrm{AD}$ had its own hiccups with only $16 \%$ of individuals with SCD progressing to clinical AD in the AMSTERDAM study, 7\%-37\% in the Mayo Clinic Study on Aging (MCSA) and 2.33\% annual progression in Mitchell et al.s study with a low relative risk of 2.07 [24-28]. Two other factors chipping away at its candidacy are that a) majority of individuals with
SCD are $>60$ years and $b$ ) $<30 \%$ of individuals with SCD test biomarker positive [29-34].

In 2019 a study inferred that the P300 an event related potential (ERP) marker was able to differentiate with $100 \%$ accuracy between individuals with new-onset Alzheimer's disease (AD) and normal subjects [35]. The study also suggested that the P300 elicited using the task-drive odd-ball paradigm recorded using electroencephalography (EEG) machines like BrainView NeuralScan could be potentially used to detect AD in the pre-clinical stage [35]. In 2019 it was estimated that 5.8 million Americans had AD [36]. In general, normal aging exhibits "decline in" - recall, episodic memory, processing speed and divided attention, while implicit memory and recognition remains "stable" with semantic memory, crystallized IQ and emotional reasoning improving till $\approx 60$ years of age [37-39]. Beginning with "loss of memory" (inability to encode or retrieve recent memories) individuals with Alzheimer's disease (AD) subsequently complain of difficulty with attention, planning, semantic memory, and abstract thinking. Further progression of $\mathrm{AD}$ results in greater memory loss, language difficulties, failure to recognize close family and friends, emotional instability and finally loss of control over bodily functions [37-39].

The present article will describe the changes in working memory (WM) and information processing in pre-clinical $\mathrm{AD}$ and $\mathrm{MCI}$

${ }^{*}$ Correspondence to: Jonathan RT Lakey, PhD, MSM, Department of Surgery, 333 City Blvd West, Suite 1600, Orange, CA 92868, USA, E-mail: jlakey@uci.edu

Received: May 29, 2020; Accepted: June 26, 2020; Published: June 29, 2020 
captured via the P300. The benefit of state-of-the art EEG machines like BrainView NeuralScan (Figure 1) is that in addition to ERPbased (i.e. P300) identification of preclinical $\mathrm{AD}$, brain mapping using quantitative electroencephalogram ( $q E E G)$, and source localization using low resolution brain electromagnetic tomography (sLORETA) imaging to identify Brodmann areas (BA) affected is possible. Thus the clinician can micro-monitor progression and titer treatments using ERPs like the P300 and at the same time be able to identify areas of the cortex that are involved which in turn allows them to anticipate which cortical functions might be compromised in the future.

\section{Working memory and Information processing}

Deficit in episodic memory is a key impairment seen in early AD. Working memory (WM) defined as "the capacity to hold information that is absent in mind for brief periods of time" [35,36]. The model consists of the central executive that controls and regulates the function of the phonological loop (articulatory loop and acoustic store), the episodic buffer and the visuospatial sketchpad; allocating attention to current relevant tasks and block out irrelevant tasks. In the WM model the three processes in memory formation include: information encoding, maintenance, and retrieval. Long-term memories are formed when information is transferred from short-term to permanent episodic representation by rehearsal $[35,36]$. Early AD memory complaints revolve around encoding, maintenance, and retrieval of information, deficits in the acquisition of new information (encoding) and retention or retrieval deficit in early AD remains equivocal [37-50],

\section{P300 and Theories on P300}

Neurocognitive functional connectivity markers like the P300 that use EEG/MEG/event related potentials) in combination with resting state or goal-driven oddball paradigms (tasks/attention/visual/auditory/ response inhibition Go/NoGO) to elicit and study brain function are sensitive [35-41,51-57]. They have the potential to demonstrate abnormal diffuse slowing, delay and suppression of responses to sensory and cognitive stimuli, identify pre-clinical $\mathrm{AD}$, in treatment evaluation be it medication (eg.: effect of acetylcholinesterase inhibitors on $\mathrm{AD}$

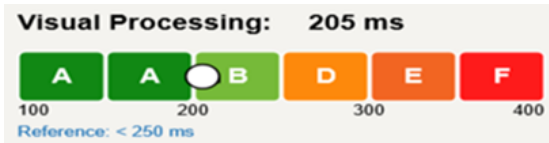

Auditory Processing: $200 \mathrm{~ms}$
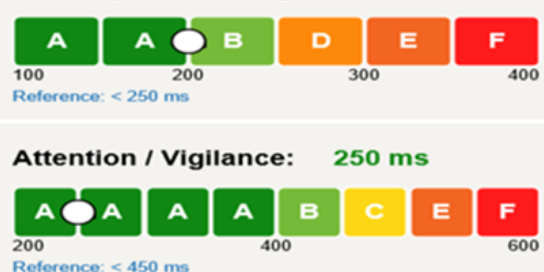

Information Processing / Working Memory:

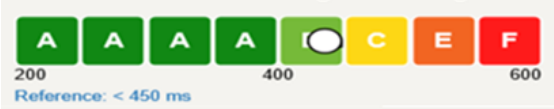

Eyes Open: Posterior Peak Frequency: $9.1 \mathrm{~Hz}$

Marker of Cognitive Performance

Reterence: $8 \cdot 12 \mathrm{~Hz}$

Eyes Closed: Posterior Peak Frequency: $9.1 \mathrm{~Hz}$

Reference: $8-12 \mathrm{~Hz}$

Eyes Open: Brain Sourcing Deviations

\begin{tabular}{|l|}
\hline Brodmann Avea \\
\hline BA Leff $1,2,3,4,6,22,41$ \\
\hline BA Right 40
\end{tabular}

Frequeng (Z-Soore)

$6 \mathrm{~Hz}(2.3 \mathrm{SD})$

$8 \mathrm{~Hz}(22 \mathrm{SD})$

Eyes Closed: Brain Sourcing Deviations

Brodmann Avea

BA Right 1, 2,3,4

$B A 6,7,8,9,10,25,33,32$

BA Left $20,30,36,37,39,40,41,42,47$

BA Leff 17, 18, 19, 31, 37
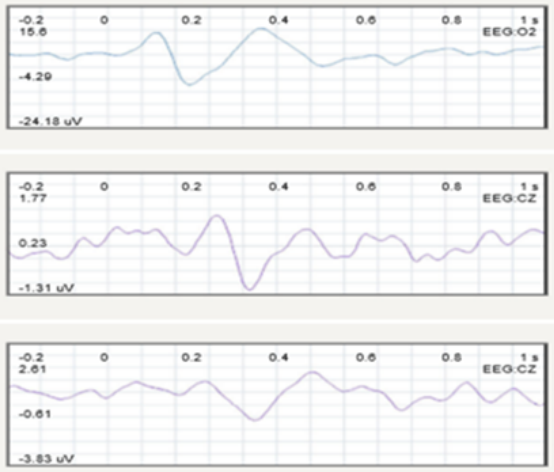

$435 \mathrm{~ms}$
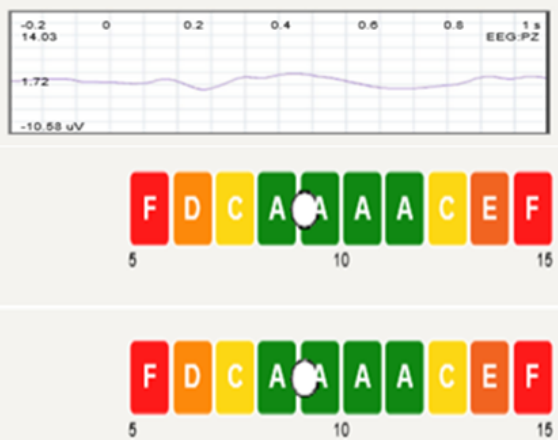

Function

Short-term memory, Coordination

Sustained attention

Function

Non-verbal memory, Coordination

Focus; Attention; Motivation

Non-verbal memory, Coordination

Sensory processing: Information processing: Working memorn

Right visual feld

Figure 1. Report summarizing the results of visual and auditory processing, attention, working memory/information processing evaluated using the P300 and resting EEG (eyes open and eyes closed) using BrainView NeuralScan by Medeia 
patients), neurofeedback or neurotherapy [35-47,51-63]. Among them, the P300 recorded using EEG machines like BrainView NeuralScan by Medeia (Figure 1) captures information processing memory, attention, executive function with the dopamine-mediated P300a playing a key role in frontal working memory (WM) function while medial temporal lobe generated P300b component, is norepinephrine-mediated $[48,49]$. P3a reflects orientation to a nontarget deviant stimulus, focal attention, engagement of attention, processing novelty executive function [5053,62-65]. Decline in P3a amplitude has been shown to correspond to decreased attention and executive function in mild $\mathrm{AD}$ indicative of its potential as a preclinical marker of $\mathrm{AD}$ and aiding clinicians in arriving at a more objective diagnosis and treatment titration [50-53,62-65].

Theories on P300 include i) stimulus evaluation hypothesis subsequently refuted [66-68], ii) Sokolov's context-updating hypothesis environment i.e. updating occurs when relevant stimuli are presented [60,69-71], iii). context-closure hypothesis namely; first consolidation of stimuli is carried out to achieve a meaningful context and when this is followed by background stimuli i.e. the meaningful event is over. closure is initiated [70,72-74]. Other trivia to keep in mind include; P300 latencies and larger amplitudes reflect superior information processing with the converse indicating decline in cognitive function $[60,70,74-78] .60 \%$ of P300 morphology observed is individual specific and stable showing little variation over recording sessions/trials and with morphology, reaction times (RTs), $75 \%$ of speed and errors positively correlated with age [79-88]. Individual variations in P300 mediated by arousal levels are guided by an individual's traits, state (natural and biological eg. body temperature, sleep quality, exercise, food intake, drugs) and physiological properties (anatomical features of the corpus callosum or skull thickness) [86-88].

\section{Systematic and meta-analytic reviews on P300}

Figure 2 illustrates the relationship between the auditory P300 and age based on both a systematic and meta-analytic review of 75 studies $(n=2811)$ [89]. Age-related degenerative effects include increase in P300 latencies and decline in amplitude [90,91]. This coupled with changes in white matter integrity influence executive dysfunction in the elderly $[90,92,93]$. To compensate for this decline older adults recruit other neural networks mediated in the prefrontal cortices to help meet the task as hand however once a particular threshold is crossed this is no longer possible and decline in cognitive performance can be seen ('CRUNCH' model) [85,94-108]. In a clinical trial on 103 with mild AD and 101 healthy controls (HC) between 60 and 90 years of age Cecchi et al. evaluated suitable ERP markers of mild AD. P3a amplitude $(\mu \mathrm{V})$ differed significantly between healthy controls $(H C, n=101) 5.88 \pm 0.19$ and those with mild AD (n=103) 3.63 $\pm 0.20^{\star *}$ following a distractor (white noise) stimulus. Latency (ms) did not appear to be significantly different between HC 417.3 \pm 2.4 and those with AD 419.8 \pm 3.0 [70]. Both P3b amplitude $(\mu \mathrm{V})$ differed significantly between healthy controls (HC) $6.03 \pm 0.20$ and those with AD 4.42 $\pm 0.20^{\star *}$ following a target $(2000 \mathrm{~Hz})$ stimulus as well as latency (ms) HC 396.0 \pm 2.8, AD 419.6 $\pm 3.3^{*}$ [109]. Pedroso et al. carried out a systematic review of 8 studies (Caravaglios et al., O'Mahony et al., Lai et al., Yamaguchi et al., Golob \& Starr, Bennys et al., Juckel et al. and Frodl et al.) that examined the auditory P300 amplitude and latency in AD [110-118]. Findings were that while P300 consistently showed an increase in latency in the elderly with AD, amplitude showed no such consistent pattern [110118]. One reason could be was a lack of standardization in the method used to elicit and capture the P300 [110-118]. However, another meta-
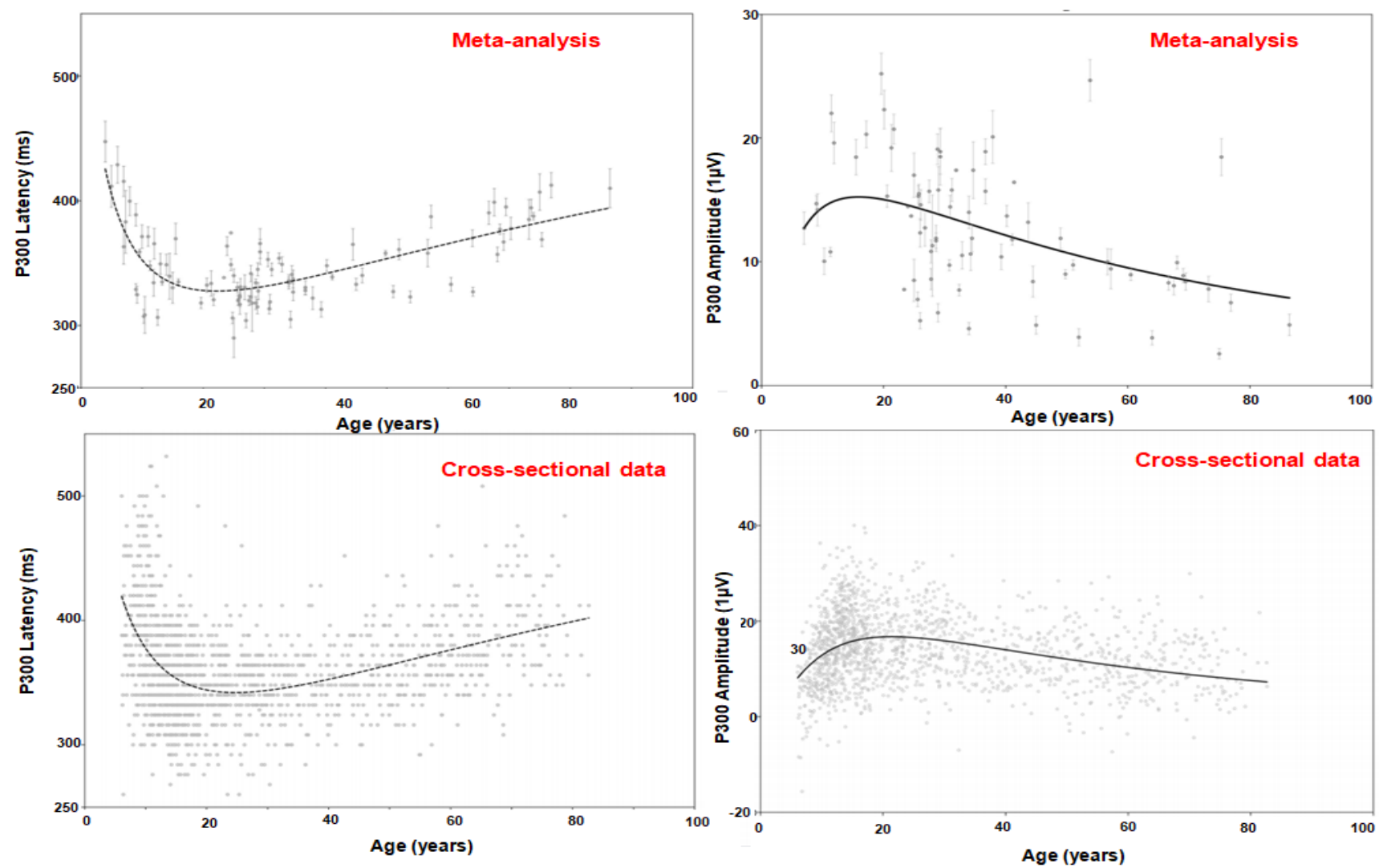

Figure 2. P300 and age [89] 
analysis and meta-regression carried out by Hedges et al. found P300 amplitude was smaller in those with $\mathrm{AD}[24]$.

\section{P300 and recording electrode}

Among studies comparing healthy elderly and those with AD three found lower P300 amplitude and two, higher P300 latency differentiated healthy elderly versus those at risk of $\mathrm{AD}$ while another found amplitude and latency were better in individuals without subjective memory complaints than those with complaints [119-126]. One study found that parietal electrodes were best at identifying changes in P300 patterns between controls, MCI and AD [125-128].

\section{P300 and treatment $(\mathrm{Rx})$ tracking}

In six studies, three on allopathic medication, another on ayurvedic medication and two on exercise, the P300 was able to capture the influence of the respective therapeutic regimen on the cognitive function of elderly [129-134]. The elderly in the clinical trial compared to the placebo/ control group showed improvements in amplitude and latency during the respective treatments and return to baseline values once they were taken off them. Figure 3 a illustrates the usefulness of the P300 in treatment tracking from a study carried out by Vaitkevičius A. 22 consecutive treatment-naïve $\mathrm{AD}$ subjects, $22 \mathrm{AD}$ on donepezil (10 mg/day) [135], and 50 healthy controls were tested using neuropsychological testing and the auditory P300 was recorded at Fz, Cz and Pz. While P300 latency and amplitude improved in the $\mathrm{AD}$ on treatment $(\mathrm{Rx})$ group. While comparison of mean $\mathrm{P} 300$ latencies $(\mathrm{p}<0.001)$ via the ANOVA was significant, both treatment-naïve $A D$ and $\mathrm{AD}$ on $\mathrm{Rx}$ differed from control group $(\mathrm{p}<0.001)$, however when treatment-naïve $\mathrm{AD}$ and $\mathrm{AD}$ on $\mathrm{Rx}$ were compared there was no significant difference seen $(\mathrm{p}=0.49)$. Predictors of P300 latency via linear regression were age $(\mathrm{p}=0.019)$ and $\operatorname{AD} \mathrm{Rx}$ status $(\mathrm{p}<0.001)$.

\section{P300 and AD-related cognitive function}

Lee et al. in a study of $31 \mathrm{HC}$ and 31 with AD found that while P300 amplitudes were lower the two study groups did not differ by latency [121]. They found the EEG recorded from the medial electrodes $\mathrm{Cz}$ and $\mathrm{Pz}$ correlated with performance levels on word list recognition, constructional praxis, and word fluency neuropsychological tests. Findings indicate that deterioration in memory, language and executive functions due to $\mathrm{AD}$ can be captured via the P300. Wang et al.'s study illustrated the use of the auditory P300 in the differential diagnosis of $\mathrm{AD}(\mathrm{n}=27)$ and behavioral variant of frontotemporal dementia (bv FTD, $n=30$ ) with those with by FTD having significantly longer P300 latency (Figure 3b) [136].

Auditory post-processing was found to be deficient in individuals with $\mathrm{AD}$ when compared to elderly controls. While this deficiency could not be explained by sensory gating, aging in general and auditory perception dysfunction; short-term memory (STM) capacity and executive control tasks instead point at possible deficits in memory encoding and/or cognitive control [137].

\section{Visually-evoked (VEP) P300}

Kuba M et al. looked at visually-evoked (VEP) P300 in electrophysiological studies that examined the effect of aging on visual cognitive processes [84]. Visual information processing was evaluated in the primary cortical visual areas and the secondary extrastriate motion processing visual cortex while cognitive function was examined

\section{a) As marker of Donepezil (10 mg/day)/cholinesterase inhibitor (ChEI) treatment ( $\mathbf{R x}$ )-dependent cognitive functions}

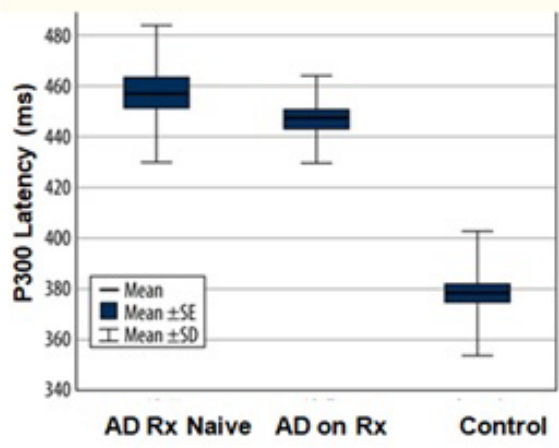

b) For differential diagnosis of $A D$ and bvFTD

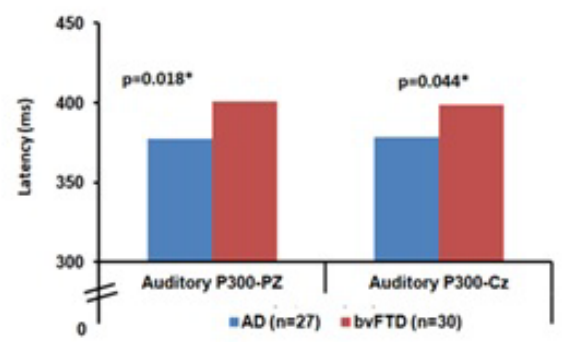

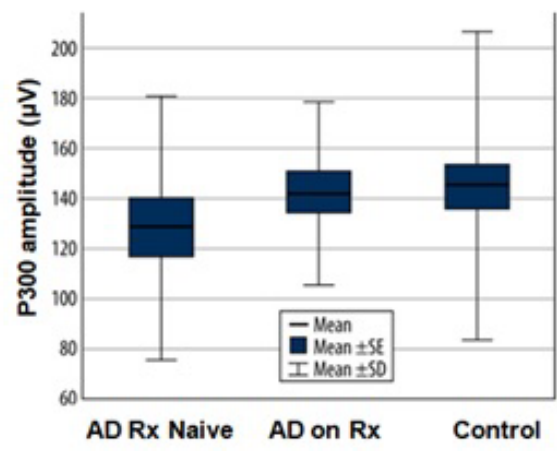

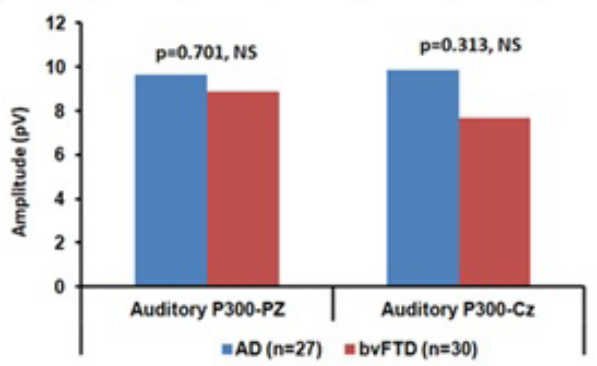

Figure 3. Comparison of mean P300 amplitude (pV) and latency (ms) $[133,136]$ 
in the centroparietal and frontal brain cortex to be able to understand visual processing in the elderly. 150 volunteers, 15 to 85 years of age, male $\%=46 \%$ with fairly good visual acuity in at least one eye were included in the study. Pattern-reversal (black/white checkerboard) and motion related VEP (translating unidirectional linear motion and radial centrifugal or centripetal motion ("expansion/contraction") were recorded from $\mathrm{Oz}, \mathrm{Pz}, \mathrm{Cz}$ and $\mathrm{Fz}$ and from $\mathrm{OL}$ and $\mathrm{OR}$ monocularly. Table 1 presents the results of the linear regression carried out to derive the equation predicting visual P300 amplitude $(\mu \mathrm{V})$ and latency $(\mathrm{ms})$ [84].

\section{P300, AD, working memory and attention}

Another study on mild dementia of the Alzheimer's type (DAT, $\mathrm{n}=10)$ and age-matched controls $(\mathrm{n}=10)$ found no difference in P1, N1, and P2 (ERPs) however P300 amplitudes were significantly reduced, reaction time retarded, and increased behavioral errors were observed [138]. The inference was in mild DAT early sensory processing including pattern recognition is intact while higher-level processing is compromised.

The P300 signature of cognitive processes such as attention and working memory is positively correlated with the amount of attentional resources assigned to a given task and its latency is negatively correlated with latencies associated with superior cognitive performance [139]. It reflects cortical activity during incoming information when it is contextually processed and incorporated. While the P300 is a measure of stimulus evaluation time it is unrelated to both response selection processes and behavioral reaction time. P300 latency increases as cognitive capability decreases from dementing illness.

Changes in the latency, amplitude, and topography of the P300 correlate with cognitive impairment in $\mathrm{AD}$. AD and MCI patients have increased P300 latency and decreased P300 amplitude compared to elderly indicating that it has the potential to identify preclinical changes

a) P300 in Encoding and Retrieval epochs

\begin{tabular}{|l|l|c|c|c|}
\hline \multicolumn{2}{|c|}{ Parameters } & MCI $(\boldsymbol{n = 2 4 )}$ & $\begin{array}{c}\text { Normal } \\
\text { control }(\boldsymbol{n}= \\
\mathbf{2 2})\end{array}$ & $\boldsymbol{p}^{*}$ \\
\hline \multirow{2}{*}{$\begin{array}{l}\text { Encoding } \\
\text { epoch }\end{array}$} & Number of valid trials & 1643 & 1637 & 0.889 \\
\cline { 2 - 5 } & Latency $(\mathrm{ms})$ & $317.69 \pm 46.51$ & $312.64 \pm 45.17$ & 0.711 \\
\cline { 2 - 5 } & Amplitude $(\mu \mathrm{V})$ & $4.37 \pm 2.66$ & $4.50 \pm 2.88$ & 0.803 \\
\hline \multirow{2}{*}{$\begin{array}{l}\text { Retrieval } \\
\text { epoch }\end{array}$} & Number of valid trials & 1642 & 1604 & 0.634 \\
\cline { 2 - 5 } & Latency $(\mathrm{ms})$ & $296.67 \pm 37.75$ & $306.54 \pm 34.80$ & 0.363 \\
\cline { 2 - 5 } & Amplitude $(\mu \mathrm{V})$ & $3.72 \pm 2.31$ & $5.45 \pm 3.14$ & $\mathbf{0 . 0 3 8 ^ { * }}$ \\
\hline
\end{tabular}

Figure 4. Early MCI: P300 and sLORETA images at P200 of aMCI versus controls illustrate central-executive-based on medial frontal gyrus retrieval deficit [141] in participants with and without a genetic predisposition to $\mathrm{AD}$ and who will convert to $\mathrm{AD}$ as well as to help evaluate of cholinesterase inhibitors treatment in dementia. P3a a frontocentrally maximal positive ERP marker of the attentional switching is generated by the prefrontal, cingulate, temporo-parietal, and hippocampal regions. $\mathrm{AD}$ patients have longer P3a latency and exhibit delayed orientation to deviant stimuli and the $\mathrm{P} 3 \mathrm{a}$ is different in $\mathrm{AD}$ compared to vascular dementia.

In a study on 200 middle-aged construction workers Portin et al. linked P300 with attentional performance (with low rather than effortful working memory demands and updating), retrieval from memory stores and or MCI [140]. Li BY et al. carried out a study on 24 subjects with MCI and 22 normal controls (Figure 4). Neuropsychological tests, delayed match to sample task (DMS task), visual P300 at O1, O1, and $\mathrm{Pz}$, and standard low-resolution tomography analysis (s-LORETA) were measured. P300 amplitude differed significantly $(p=0.025$ and $p=0.038$ ) for the retrieval epoch [141]. Positive correlation was found between P300 amplitude and memory load, language fluency and visual-spatial ability. Findings suggest that P300 might represent general cognitive ability, while P2 correlated with attention allocation via sLORETA and early $\mathrm{AD} / \mathrm{MCI}$ are marked by retrieval deficit.

Table 1. Linear regression co-ordinates predicting Visual Evoked P300 potential (VEP) $[84]$

\begin{tabular}{|c|c|c|}
\hline \multicolumn{1}{|c|}{$\mathbf{n}$} & Visual P300 (y-axis) & Intercept (c), Slope (m), $\mathbf{R}^{2}, \mathbf{p}$-value \\
\hline \multirow{2}{*}{ Whole Group $(\mathrm{n}=150)$} & Latency $(\mathrm{ms})$ & $324.5,2.005,0.601, \mathrm{p}=0.001$ \\
\cline { 2 - 3 } & Amplitude $(\mu \mathrm{V})$ & $21.9,-0.161,0.255, \mathrm{p}=0.001$ \\
\hline \multirow{2}{*}{$\begin{array}{c}\text { Males } \\
(\mathrm{n}=69)\end{array}$} & Latency $(\mathrm{ms})$ & $336.9,1.600,0.515, \mathrm{p}=0.001$ \\
\cline { 2 - 3 } $\begin{array}{c}\text { Female } \\
(\mathrm{n}=81)\end{array}$ & Amplitude $(\mu \mathrm{V})$ & $22.3,-0.175,0.263, \mathrm{p}=0.001$ \\
\cline { 2 - 3 } & Latency $(\mathrm{ms})$ & $314.7,2.336,0.676, \mathrm{p}=0.001$ \\
\hline
\end{tabular}

b) sLORETA images showing positive differences between aMCl and controls (in yellow) (3D-view, slice-view, P200 time-range; Montreal Neurological Institute (MNI) coordinates $x, y, z=25,45,-10$ )

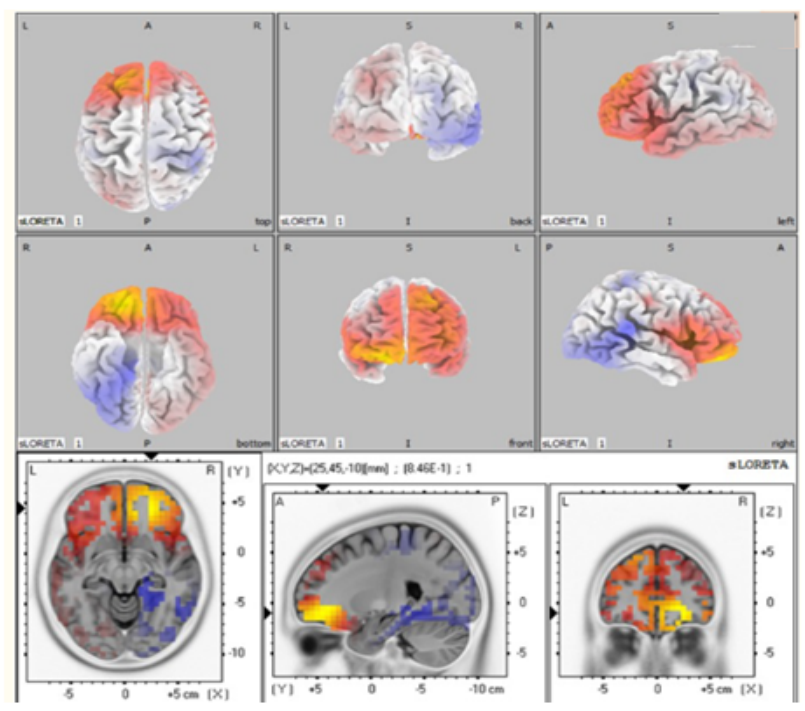




\section{Conclusion}

The criteria delineating the stages of progression from pre clinical to clinical $\mathrm{AD}$ remain to be fully characterized and defined, and earlier identification i.e. at the stage of early MCI would greatly augment the implementation of earlier and potentially more efficacious treatment, delay or even prevention of $\mathrm{AD}$. More recent advancements in the field have led to a refocusing of efforts to emphasize identifying individuals at risk for $\mathrm{AD}$ development. The present article explored the utility of state-of-the-art new innovations including EEG machines such as the BrainView NeuralScan in identifying individuals at preclinical risk of $\mathrm{AD}$, citing their unique capability to identify key hallmarks through such measure's oddball paradigm elicited P300 morphology, amplitude and latency recording. While the ability of the P300 to aid in identifying those at risk of preclinical $\mathrm{AD}$ or $\mathrm{MCI}$ is well-documented, there remains a need to standardize paradigms used to elicit the P300, and while there are many studies on the auditory as well as the visual P300, a more comprehensive identification of P300 changes correlating to specific symptoms will need to be established within the context of a preclinical AD to maximize these devices' full potential for diagnostic, prognostic and therapeutic-guidance benefit.

\section{References}

1. https://www.khanacademy.org/science/health-and-medicine/executive-systems-of-thebrain/memory-lesson/v/alzheimer-s-disease-and-korsakoff-s-syndrome.

2. Amariglio RE, Becker JA, Carmasin J, Wadsworth LP, Lorius N, et al. (2012) Subjective cognitive complaints and amyloid burden in cognitively normal older individuals. Neuropsychologia 50: 2880-2886. [Crossref]

3. Chetelat G, Villemagne VL, Bourgeat P, Pike KE, Jones G, et al. (2010) Relationship between atrophy and beta-amyloid deposition in Alzheimer disease. Ann Neurol 67: 317-324. [Crossref]

4. Norton S, Matthews FE, Barnes DE, Yaffe K, Brayne C, et al. (2014) Potential for primary prevention of Alzheimer's disease: An analysis of population-based data. Lancet Neurol 13: 788-794. [Crossref]

5. Imtiaz B, Tolppanen AM, Kivipelto M, Soininen H (2014) Future directions in Alzheimer's disease from risk factors to prevention. Biochem Pharmacol 88: 661-670.

6. Deckers K, van Boxtel MP, Schiepers OJ, de Vugt M, Munoz Sanchez JL, et al. (2015) Target risk factors for dementia prevention: a systematic review and Delphi consensus study on the evidence from observational studies. Int J Geriatr Psychiatry 30: 234-246.

7. Vemuri P, Lesnick TG, Przybelski SA, Knopman DS, Preboske GM, et al. (2015) Vascular and amyloid pathologies are independent predictors of cognitive decline in normal elderly. Brain 138: 761-71. [Crossref]

8. Barnard ND, Bush AI, Ceccarelli A, Cooper J, de Jager CA, et al. (2014) Dietary and lifestyle guidelines for the prevention of Alzheimer's disease. Neurobiol Aging 35: S74-S78.

9. Solomon A, Mangialasche F, Richard E, Andrieu S, Bennett DA, et al. (2014) Advances in the prevention of Alzheimer's disease and dementia. J Intern Med 275: 229-250.

10. Ngandu T, Lehtisalo J, Solomon A, Levalahti E, Ahtiluoto S, et al. (2015) A 2 year multidomain intervention of diet, exercise, cognitive training, and vascular risk monitoring versus control to prevent cognitive decline in at-risk elderly people (FINGER): a randomized controlled trial. Lancet 385: 2255-2263. [Crossref]

11. Matthews DC, Davies M, Murray J, Williams S, Tsui WH, et al. (2014) Physical Activity, Mediterranean Diet and Biomarkers-Assessed Risk of Alzheimer's: A MultiModality Brain Imaging Study. Adv J Mol Imaging 4: 43-57.

12. Erickson KI, Voss MW, Prakash RS, Basak C, Szabo A, et al. (2011) Exercise training increases size of hippocampus and improves memory. Proc Natl Acad Sci U S A 108: 3017- 3022 .

13. Okonkwo OC, Schultz SA, Oh JM, Larson J, Edwards D, et al. (2014) Physical activity attenuates age-related biomarker alterations in preclinical AD. Neurology 83: 17531760.

14. Mosconi L, Murray J, Tsui WH, Li Y, Davies M, et al. (2014) Mediterranean Diet and Magnetic Resonance Imaging-Assessed Brain Atrophy in Cognitively Normal Individuals at Risk for Alzheimer's Disease. J Prev Alzheimers Dis 1: 23-32.
15. Jack CR Jr, Knopman DS, Jagust WJ, Shaw LM, Aisen PS, et al. (2010) Hypothetical model of dynamic biomarkers of the Alzheimer's pathological cascade. Lancet Neurol 9: 119-128. [Crossref]

16. Sperling RA, Aisen PS, Beckett LA, Bennett DA, Craft S, et al. (2011) Toward defining the preclinical stages of Alzheimer's disease: recommendations from the National Institute on Aging-Alzheimer's Association workgroups on diagnostic guidelines for Alzheimer's disease. Alzheimers Dement 7: 280-292.

17. Bateman RJ, Xiong C, Benzinger TL, Fagan AM, Goate A, et al. (2012) Clinical and biomarker changes in dominantly inherited Alzheimer's disease. N Engl J Med 367: 795-804.

18. Amieva H, Le Goff M, Millet X, Orgogozo JM, Peres K, et al. (2008) Prodroma Alzheimer's disease: successive emergence of the clinical symptoms. Ann Neurol 64: 492-498.

19. Amieva H, Mokri H, Le Goff M, Meillon C, Jacqmin-Gadda H, et al. (2014) Compensatory mechanisms in higher-educated subjects with Alzheimer's disease: a study of 20 years of cognitive decline. Brain 137: 1167-1175. [Crossref]

20. Henry J, Crawford JR (2005) A meta-analytic review of verbal fluency deficits in depression. J Clin Exp Neuropsychol 27: 78-101.

21. Beheydt LL, Schrijvers D, Docx L, Bouckaert F, Hulstijn W, et al. (2014) Psychomotor retardation in elderly untreated depressed patients. Front Psychiatry 5: 196.

22. van Holst RJ, Schilt T (2011) Drug-related decrease in neuropsychological functions of abstinent drug users. Curr Drug Abuse Rev 4: 42-56.

23. Koster DP, Higginson CI, MacDougall EE, Wheelock VL, Sigvardt KA, et al. (2015) Subjective Cognitive Complaints in Parkinson Disease Without Dementia: A Preliminary Study. Appl Neuropsychol Adult 22: 287-292.

24. Jessen F, Amariglio RE, van Boxtel M, Breteler M, Ceccaldi M, et al. (2014) A conceptual framework for research on subjective cognitive decline in preclinical Alzheimer's disease. Alzheimers Dement 10: 844-852.

25. Gallassi R, Oppi F, Poda R, Scortichini S, Stanzani Maserati M, et al. (2010) Are subjective cognitive complaints a risk factor for dementia? Neurol Sci 31: 327-336.

26. Mielke MM, Wiste HJ, Weigand SD, Knopman DS, Lowe VJ, et al. (2012) Indicators of amyloid burden in a population-based study of cognitively normal elderly. Neurology 79: 1570-1577. [Crossref]

27. Mitchell AJ, Beaumont H, Ferguson D, Yadegarfar M, Stubbs B, et al. (2014) Risk of dementia and mild cognitive impairment in older people with subjective memory complaints: meta-analysis. Acta Psychiatr Scand 130: 439-451.

28. Pike KE, Ellis KA, Villemagne VL, Good N, Chetelat G, et al. (2011) Cognition and betaamyloid in preclinical Alzheimer's disease: data from the AIBL study. Neuropsychologia 49: 2384-2390.

29. Berman S, Lowenthal JP, Sorrentino JV, White AB (1967) A safety test for Eastern equine encephalomyelitis vaccine. Appl Microbiol 15: 968-969.

30. Baddeley A (2012) Working memory: theories, models, and controversies. Annu Rev Psychol 63: 1-29.

31. Baddeley AD (2001) Is working memory still working? Am Psychol 56: 851-864.

32. Aggarwal NT (2005) Mild co35gnitive impairment in different functional domains and incident Alzheimer's disease. J Neurol Neurosurg Psychiatr 76: 1479-1484. [Crossref]

33. Pasquier F, Grymonprez L, Lebert F, Van der Linden M (2001) Memory impairment differs in frontotemporal dementia and Alzheimer's disease. Neurocase 7: 161-171.

34. Grober E, Kawas C (1997) Learning and retention in preclinical and early Alzheimer's disease. Psychol. Aging 12: 183-188.

35. Jervis BW, Bigan C, Jervis MW, Besleaga M (2019) New-Onset Alzheimer's Disease and Normal Subjects 100\% Differentiated by P300. Am J Alzheimers Dis Other Demen 34: 308-313.

36. Hebert LE, Weuve J, Scherr PA, Evans DA (2013) Alzheimer disease in the United States (2010-2050) estimated using the 2010 Census. Neurology 80: 1778-1783.

37. Dubois B, Feldman HH, Jacova C, Cummings JL, Dekosky ST, et al. (2010) Revising the definition of Alzheimer's disease: a new lexicon. Lancet Neurol 9: 1118-1127.

38. https://www.khanacademy.org/science/health-and-medicine/executive-systems-of-thebrain/memory-lesson/v/information-processing-model-sensory-working-and-longterm-memory.

39. https://www.khanacademy.org/science/health-and-medicine/executive-systems-of-thebrain/memory-lesson/v/aging-and-cognitive-abilities. 
40. Albert MS, Moss MB, Tanzi R, Jones K (2001) Preclinical prediction of AD using neuropsychological tests. J Int Neuropsychol Soc 7: 631-639.

41. Crawford LE, Landy D, Salthouse TA (2016) Spatial working memory capacity predicts bias in estimates of location. J Exp Psychol Learn Mem Cogn 42: 1434-1447.

42. Salthouse TA (1994) The aging of working memory. Neuropsychology 8: 535-543.

43. Pinal D, Zurrón M, Díaz F (2015) Age-related changes in brain activity are specific for high order cognitive processes during successful encoding of information in working memory. Front Aging Neurosci 7: 75. Published 2015 May 11.

44. Saliasi E, Geerligs L, Lorist MM, Maurits NM (2013) The relationship between P3 amplitude and working memory performance differs in young and older adults. PLoS One 8: e63701. [Crossref]

45. Cespón J, Galdo-Álvarez S, Díaz F (2018) Event-Related potentials reveal altered executive control activity in healthy elderly with subjective memory complaints. Front Hum Neurosci 12: 445.

46. Pinal D, Zurrón M, Díaz F (2015) An Event Related Potentials Study of the Effects of Age, Load and Maintenance Duration on Working Memory Recognition. PLoS ONE 10: e0143117.

47. Kirova AM, Bays RB, Lagalwar S (2015) Working memory and executive function decline across normal aging, mild cognitive impairment, and Alzheimer's disease. Biomed Res Int 2015: 748212.

48. Jahn H (2013) Memory loss in Alzheimer's disease. Dialogues Clin Neurosci 15: 445 454.

49. Huntley JD, Howard RJ (2010) Working memory in early Alzheimer's disease: a neuropsychological review. Int J Geriatr Psychiatry 25: 121-132. [Crossref]

50. Miller EK, Lundqvist M, Bastos AM (2018) Working Memory 2.0. Neuron 100: 463 475 .

51. Van Straaten EC, Scheltens P, Gouw AA, Stam CJ (2014) Eyes-closed task-free electroencephalography in clinical trials for Alzheimer's disease: an emerging method based upon brain dynamics. Alzheimers Res Ther 6: 86 .

52. Alonso JF, Poza J, Mananas MA, Romero S, Fernandez A, et al. (2011) MEG connectivity analysis in patients with Alzheimer's disease using cross mutual information and spectral coherence. Ann Biomed Eng 39: 524-536.

53. Bajo R, Maestu F, Nevado A, Sancho M, Gutierrez R, et al. (2010) Functional connectivity in mild cognitive impairment during a memory task: implications for the disconnection hypothesis. J Alzheimers Dis 22: 183-193.

54. Hsiao FJ, Wang YJ, Yan SH, Chen WT, Lin YY, et al. (2013) Altered oscillation and synchronization of default-mode network activity in mild Alzheimer's disease compared to mild cognitive impairment: an electro-physiological study. PLoS One 8: e68792.

55. Babiloni C, Lizio R, Marzano N (2016) Brain neural synchronization and functional coupling in Alzheimer's disease as revealed by resting state EEG rhythms. Int $J$ Psychophysiol 103: 88-102.

56. Stam CJ, Jones BF, Manshanden I, van Cappellen van Walsum AM, et al. (2006) Magnetoencephalographic evaluation of resting-state functional connectivity in Alzheimer's disease. Neuro-image 32: 1335-1344.

57. Engels MM, Stam CJ, van der Flier WM, Scheltens P, de Waal H, et al. (2015) Declining functional connectivity and changing hub locations in Alzheimer's disease: an EEG study. BMC Neurol 15: 145.

58. Saletu B, Anderer P, Saletu-Zyhlarz GM (2010) EEG topography and tomography (LORETA) in diagnosis and pharmacotherapy of depression. Clin EEG Neurosci 41: 203-210. [Crossref]

59. Nishida K, Yoshimura M, Isotani T (2011) Differences in quantitative EEG between frontotemporal dementia and Alzheimer's disease as revealed by LORETA. Clin Neurophysiol 122: 1718-1725.

60. Polich J (2004) Clinical application of the P300 event-related brain potential. Phys Med Rehabil Clin N Am 15: 133-161.

61. Onofrj M, Thomas A, Iacono D, Luciano AL, Di Iorio A, et al. (2003) The effects of a cholinesterase inhibitor are prominent in patients with fluctuating cognition: a part 3 study of the main mechanism of cholinesterase inhibitors in dementia. Clin Neuropharmacol 26: 239-251.

62. Onofrj M, Thomas A, Luciano AL (2002) Donepezil versus vitamin E in Alzheimer's disease: Part 2: mild versus moderate-severe Alzheimer's disease. Clin Neuropharmacol 25: 207-215.
63. Thomas A, Iacono D, Bonanni L, D'Andreamatteo G, Onofrj M, et al. (2001) Donepezil rivastigmine, and vitamin $\mathrm{E}$ in Alzheimer disease: a combined P300 event-related potential/neuropsychologic evaluation over 6 months. Clin Neuropharmacol 24: 31-42.

64. Hansenne M (2000) The p300 Cognitive Event-Related Potential. II. Individual Variability and Clinical Application in Psychopathology. Neurophysiol Clin 30: 211-231.

65. Simons JS, Spiers HJ (2003) Prefrontal and medial temporal lobe interactions in longterm memory. Nat Rev Neurosci 4: 637-648.

66. Duncan-Johnson CC, Kopell BS (1981) The Stroop effect: brain potentials localize the source of interference. Science 214: 938-940.

67. Verleger R (2010) Popper and P300: Can the view ever be falsified that P3 latency is a specific indicator of stimulus evaluation? Clin Neurophysiol 121: 1371-1372. [Crossref]

68. Verleger R (1997) On the utility of P3 latency as an index of mental chronometry Psychophysiology 34: 131-156.

69. Polich J (2007) Updating P300: an integrative theory of P3a and P3b. Clin Neurophysiol 118: $2128-2148$

70. Polich J (1996) Meta-analysis of P300 normative aging studies. Psychophysiology 33 334-353.

71. Donchin E (1981) Presidential address, 1980. Surprise? Surprise? Psychophysiology 18: 493-513. [Crossref]

72. Niedermeyer E, Lopes da Silva F (1999) Electroencephalography: basic principles, clinical applications, and related fields. Baltimore: Williams \& Wilkins 1999.

73. Verleger R (1988) Event-related potentials and cognition: A critique of the context updating hypothesis and an alternative interpretation of P3. Behavioral and Brain Sciences 11: 343-356.

74. Altenmuller EO, Gerloff G (1998) Psychophysiology and EEG, in: Niedermeyer E, Da Silva FHL. Electroencephalography: basic principles, clinical applications, and related fields. Lippincott Williams \& Wilkins 2004.

75. Walhovd KB, Fjell AM (2001) Two- and three-stimuli auditory oddball ERP tasks and neuropsychological measures in aging. Neuroreport 12: 3149-3153. [Crossref]

76. Shajahan PM, O'Carroll RE, Glabus MF, Ebmeier KP, Blackwood DH, et al. (1997) Correlation of auditory 'oddball' P300 with verbal memory deficits in schizophrenia. Psychol Med 27: 579-586. [Crossref]

77. Fjell AM, Walhovd KB (2003) 1Effects of auditory stimulus intensity and hearing threshold on the relationship among P300, age, and cognitive function. Clin Neurophysiol 114: 799-807.

78. Sachs G, Anderer P, Margreiter N, Semlitsch H, Saletu B, et al. (2004) P300 eventrelated potentials and cognitive function in social phobia. Psychiatry Res 131: 249-261.

79. Williams LM, Simms E, Clark CR, Paul RH, Rowe D, et al. (2005) The test-retest reliability of a standardized neurocognitive and neurophysiological test battery: "neuromarker". Int J Neurosci 115: 1605-1630.

80. van Beijsterveldt CE, van Baal GC (2002) Twin and family studies of the human electroencephalogram: a review and a meta-analysis. Biol Psychol 61: 111-138

81. Walhovd KB, Rosquist H, Fjell AM (2008) P300 amplitude age reductions are not caused by latency jitter. Psychophysiology 45: 545-553.

82. Rossini PM, Rossi S, Babiloni C, Polich J (2007) Clinical neurophysiology of aging brain: from normal aging to neurodegeneration. Prog Neurobiol 83: 375- 400.

83. Ashford JW, Coburn KL, Rose TL, Bayley PJ (2011) P300 energy loss in aging and Alzheimer's disease. J Alzheimers Dis 26: 229-238.

84. Kuba M, Kremla'c ček J, Langrova' J, Kubova' Z, Szanyi J, et al. (2012) Aging effect in pattern, motion and cognitive visual evoked potentials. Vision Res 62C: 9-16.

85. Salthouse TA (2000) Aging and measures of processing speed. Biol Psychol 54: 35-54 [Crossref]

86. Polich J, Kok A (1995) Cognitive and biological determinants of P300: an integrative review. Biol Psychol 41: 103-146.

87. Huster RJ, Westerhausen R, Herrmann CS (2011) Sex differences in cognitive control are associated with midcingulate and callosal morphology. Brain Struct Funct 215 : 225-235. [Crossref]

88. Frodl T, Meisenzahl EM, Mu“ller D, Leinsinger G, Juckel G, et al. (2001) The effect of the skull on event-related P300. Clin Neurophysiol 112: 1773-1776. [Crossref] 
89. van Dinteren R, Arns M, Jongsma ML, Kessels RP (2014) P300 development across the lifespan: a systematic review and meta-analysis. PLoS One 9: e87347.

90. Fjell AM, Walhovd KB (2001) P300 and neuropsychological tests as measures of aging: Scalp topography and cognitive changes. Brain Topogr 14: 25-40. [Crossref]

91. Baudic S, Barba GD, Thibaudet MC, Smagghe A, Remy P, et al. (2006) Executive function deficits in early Alzheimer's disease and their relations with episodic memory. Arch Clin Neuropsychol 21: 15-21.

92. Brickman AM, Meier IB, Korgaonkar MS (2012) Testing the white matter retrogenesis hypothesis of cognitive aging. Neurobiol Aging 33: 1699-1715.

93. Davatzikos C, Resnick SM (2002) Degenerative age changes in white matter connectivity visualized in vivo using magnetic resonance imaging. Cereb Cortex 12: 767-771.

94. Daffner KR, Chong H, Sun X (2011) Mechanisms underlying age- and performancerelated differences in working memory. J Cogn Neurosci 23: 1298-1314. [Crossref]

95. Salthouse TA (1996) The processing-speed theory of adult age differences in cognition. Psychol Rev 103: 403-428.

96. Reuter-Lorenz PA, Cappell KA (2008) Neurocognitive Aging and the Compensation Hypothesis. Current Directions in Psychological Science 17: 177-182.

97. Schneider-Garces NJ, Gordon BA, Brumback-Peltz CR (2010) Span, CRUNCH, and beyond: working memory capacity and the aging brain. J Cogn Neurosci 22: 655-669. [Crossref]

98. Vermeij A, van Beek AH, Olde Rikkert MG, Claassen JA, Kessels RP, et al. (2012) Effects of aging on cerebral oxygenation during working-memory performance: a functional near-infrared spectroscopy study. PLoS One 7: e46210.

99. Davis SW, Dennis NA, Daselaar SM, Fleck MS, Cabeza R, et al. (2008) Que PASA? The posterior-anterior shift in aging. Cereb Cortex 18: 1201-1209.

100. Friedman D, Kazmerski V, Fabiani M (1997) An overview of age-related changes in the scalp distribution of P3b. Electroencephalogr Clin Neurophysiol 104: 498-513.

101. CaselliRJ, Dueck AC, Locke DE, Hoffman-SnyderCR, Woodruff BK, et al. (2011) Longitudinal modeling of frontal cognition in APOE 34 homozygotes, heterozygotes, and noncarriers. Neurology 76: 1383-1388.

102. Lim YY, Maruff P, Pietrzak RH, Ames D, Ellis KA, et al. (2014) Effect of amyloid on memory and non-memory decline from preclinical to clinical Alzheimer's disease. Brain 137: 221-231.

103. Buckner RL (2004) Memory and executive function in aging and AD: multiple factors that cause decline and reserve factors that compensate. Neuron 44: 195-208.

104. Cabeza R, Anderson ND, Locantore JK, McIntosh AR (2002) Aging gracefully: compensatory brain activity in high-performing older adults. Neuroimage 17: 1394-1402.

105. Park DC, Reuter-Lorenz P (2009) The adaptive brain: aging and neurocognitive scaffolding. Annu Rev Psychol 60: 173-196.

106. West R, Schwarb H, Johnson BN (2010) The influence of age and individual differences in executive function on stimulus processing in the oddball task. Cortex 46: 550-563.

107. Li L, Gratton C, Fabiani M, Knight RT (2013) Age-related frontoparietal changes during the control of bottom-up and top-down attention: an ERP study. Neurobiol Aging 34: 477-488.

108. O'Connell RG, Balsters JH, Kilcullen SM (2012) A simultaneous ERP/fMRI investigation of the P300 aging effect. Neurobiol Aging 33: 2448-2461. [Crossref]

109. Cecchi M, Moore DK, Sadowsky CH (2015) A clinical trial to validate event-related potential markers of Alzheimer's disease in outpatient settings. Alzheimers Dement (Amst) 1: 387-394.

110. Pedroso RV, Fraga FJ, Corazza DI, Andreatto CAA, Coelho FG de M, et al. (2012) Latência e amplitude do P300 auditivo na doença de Alzheimer: uma revisão sistemática. Braz J Otorhinolaryngol 78: 126-132.

111. Caravaglios G, Costanzo E, Palermo F, Muscoso, EG (2008) Decreased amplitude of auditory event-related delta responses in Alzheimers disease. Int J Psychophysiol 70: $23-32$.

112. O'Mahony D, Coffey J, Murphy J, OHare N, Hamilton D, et al. (1996) Event-related potential prolongation in Alzheimers disease signifies frontal lobe impairment: evidence from SPECT imaging. J Gerontol A Biol Sci Med Sci 51: 102-107.
113. Lai CL, Lin RT, Liou LM, Liu CK (2010) The role of event-related potentials in cognitive decline in Alzheimer's Disease. Clin Neurophysiol 121: 194-199.

114. Yamaguchi S, Tsuchiya H, Yamagata S, Toyoda G, Kobayashi S, et al. (2000) Eventrelated brain potentials in response to novel sounds in dementia. Clin Neurophysiol 111: $195-203$

115. Golob EJ, Starr A (2000) Effects of stimulus sequence on event-related potentials and reaction time during target detection in Alzheimer's Disease. Clin Neurophysiol 111 1438-1449. [Crossref]

116. Bennys K, Portet F, Touchon J, Rondouin G (2007) Diagnostic value of event related evoked potentials N200 and P300 subcomponents in early diagnosis of Alzheimer's disease and mild cognitive impairment. J Clin Neurophysiol 24: 405-412.

117. Juckel G, Clotz F, Frodl T, Kawohl W, Hampel H, et al. (2008) Diagnostic usefulness of cognitive auditory event-related P300 subcomponents in patients with Alzheimers disease? J Clin Neurophysiol 25: 147-52.

118. Frodl T, Hampel H, Juckel G, Bürger K, Padberg F, et al. (2002) Value of eventrelated P300 subcomponents in the clinical diagnosis of mild cognitive impairment and Alzheimer's disease. Psychophysiology 39: 175-181.

119. Pavarini SCI, Brigola AG, Luchesi BM (2018) On the use of the P300 as a tool for cognitive processing assessment in healthy aging: A review. Dement Neuropsychol 12: 1-11. [Crossref]

120. Asaumi Y, Morita K, Nakashima Y, Muraoka A, Uchimura N, et al. (2014) Evaluation of P300 components for emotion-loaded visual event-related potential in elderly subjects, including those with dementia. Psychiatry Clin Neurosci 68: 558-567.

121. Lee M-S, Lee S-H, Moon E-O, Moon Y-J, Kim S, et al. (2006) Neuropsychological correlates of the P300 in patients with Alzheimer's disease. Prog Neuropsychopharmacol Biol Psychiatry 40: 62-69.

122. Bender S, Bluschke A, Dippel G, Rupp A, Weisbrod M, et al. (2014) Auditory post-processing in a passive listening task is deficient in Alzheimer's disease. Clin Neurophysiol 125: 53-62.

123. Smart CM, Segalowitz SJ, Mulligan BP, MacDonald SWS (2014) Attention capacity and self-report of subjective cognitive decline: A P3 ERP study. Biol Psychol 103 . 144-151.

124. Hedges D, Janis R, Mickelson S, Keith C, Bennett D, et al. (2016) P300 Amplitude in Alzheimer's Disease: A Meta-Analysis and Meta-Regression. Clin EEG Neurosci 47: 48-55.

125. Jiang S, Qu C, Wang F, Liu Y, Qiao Z, et al. (2015) Using event related potential $\mathrm{P} 300$ as an electrophysiological marker for differential diagnosis and to predict the progression of mild cognitive impairment: a meta-analysis. Neurol Sci 36: 1105-1112.

126. Cintra MTG, Silva Tavares MC, Gomes SA, Gonçalves TO, Cunha LCM, et al (2015) P300 Evoked Potential and Risk of Mild Cognitive Impairment Progression to Alzheimers Dementia: A Literature Review. Journal of Neurology \& Neurophysiology 6: $1-5$.

127. Gutiérrez Giraldo N, Rangel Galvis CE, Tovar C (2013) Cognitive Evoked Potentia Measurement, P300, in a group of healthy Colombian individuals. Rev Ciencias la Salud 11: 195-204.

128. McDowell K, Kerick SE, Santa Maria DL, Hatfield BD (2003) Aging, physical activity, and cognitive processing: an examination of P300. Neurobiol Aging 24: 597 606.

129. Wang W, Qiu C, Ota T, Swada M, Kishimoto N, et al. (2013) Effects of Tai Chi Exercise on the healthy elderly as measured by event-related potentials. J Nara Med Assoc 64: 87-94.

130. Zhang X, Ni X, Chen P (2014) Study about the effects of different fitness sports on cognitive function and emotion of the aged. Cell Biochem Biophys 70: 1591-1596. [Crossref]

131. Peth-Nui T, Wattanathorn J, Muchimapura S, Tong-Un T, Piyavhatkul N, et al. (2012) Effects of 12-week bacopa monnieri consumption on attention, cognitive processing, working memory, and functions of both cholinergic and monoaminergic systems in healthy elderly volunteers. Evidence-based Complement Altern Med.

132. Tokuda H, Kontani M, Kawashima H, Akimoto K, Kusumoto A, et al. (2014) Arachidonic acid-enriched triacylglycerol improves cognitive function in elderly with low serum levels of arachidonic acid. J Oleo Sci 63: 219-227.

133. Vaitkevičius A, Kaubrys G, Audronytė E (2015) Distinctive Effect of Donepezi Treatment on P300 and N200 Subcomponents of Auditory Event-Related Evoked Potentials in Alzheimer Disease Patients. Med Sci Monit 21: 1920-1927. 
134. Paci C, Gobbato R, Carboni T, Sanguigni S, Santone A, et al. (206) P300 auditory event-related potentials and neuropsychological study during donepezil treatment in vascular dementia. Neurol Sci Off J Ital Neurol Soc Ital Soc Clin Neurophysiol 26: 435-437.

135. Smits LL, Pijnenburg YA, Koedam EL (2012) Early onset Alzheimer's disease is associated with a distinct neuropsychological profile. J Alzheimers Dis 30: 101-108.

136. Wang P, Zhang H, Han L, Zhou Y (2016) Cortical function in Alzheimer's disease and frontotemporal dementia. Transl Neurosci 7: 116-125.

137. Bender S, Bluschke A, Dippel G, Rupp A, Weisbrod M, et al. (2014) Auditory post-processing in a passive listening task is deficient in Alzheimer's disease. Clin Neurophysiol 125: 53-62. [Crossref]
138. Saito H, Yamazaki H, Matsuoka H (2001) Visual event-related potential in mild dementia of the Alzheimer's type. Psychiatry Clin Neurosci 55: 365-371.

139. Vecchio F, Määttä S (2011) The use of auditory event-related potentials in Alzheimer's disease diagnosis. Int J Alzheimers Di 3: 653173.

140. Portin R, Kovala T, Polo-Kantola P, Revonsuo A, Müller K, et al. (2000) Does P3 reflect attentional or memory performances, or cognition more generally? Scand J Psychol 41: 31-40.

141. Li BY, Tang HD, Chen SD (2016) Retrieval Deficiency in Brain Activity of Working Memory in Amnesic Mild Cognitive Impairment Patients: A Brain Event-Related Potentials Study. Front Aging Neurosci 8: 54. [Crossref]

Copyright: (C2020 Miranda P. This is an open-access article distributed under the terms of the Creative Commons Attribution License, which permits unrestricted use, distribution, and reproduction in any medium, provided the original author and source are credited. 